\title{
The spatial distribution of earthquake stress rotations following large subduction zone earthquakes
}

\author{
Jeanne L. Hardebeck ${ }^{*}$ (D)
}

\begin{abstract}
Rotations of the principal stress axes due to great subduction zone earthquakes have been used to infer low differential stress and near-complete stress drop. The spatial distribution of coseismic and postseismic stress rotation as a function of depth and along-strike distance is explored for three recent $M \geq 8.8$ subduction megathrust earthquakes. In the down-dip direction, the largest coseismic stress rotations are found just above the Moho depth of the overriding plate. This zone has been identified as hosting large patches of large slip in great earthquakes, based on the lack of high-frequency radiated energy. The large continuous slip patches may facilitate near-complete stress drop. There is seismological evidence for high fluid pressures in the subducted slab around the Moho depth of the overriding plate, suggesting low differential stress levels in this zone due to high fluid pressure, also facilitating stress rotations. The coseismic stress rotations have similar along-strike extent as the mainshock rupture. Postseismic stress rotations tend to occur in the same locations as the coseismic stress rotations, probably due to the very low remaining differential stress following the near-complete coseismic stress drop. The spatial complexity of the observed stress changes suggests that an analytical solution for finding the differential stress from the coseismic stress rotation may be overly simplistic, and that modeling of the full spatial distribution of the mainshock static stress changes is necessary.
\end{abstract}

Keywords: Stress, Subduction zone, Fault strength

\section{Introduction}

The stresses in the Earth's lithosphere are the driving forces of crustal deformation. The stresses acting on the subduction zone plate interface influence the dynamics of great megathrust earthquakes, as well as seismic and aseismic deformation throughout the seismic cycle. Direct measurement of stress in boreholes is costly and limited to relatively shallow depths, so indirect measurements must also be used. Earthquake moment tensors can be inverted for the orientation and relative amplitude of the principal stress axes, but cannot determine the absolute amplitude of the differential stress. Coseismic stress rotations due to major earthquakes are one way to indirectly measure the differential stress level: If the differential stress is on the order of earthquake stress

\footnotetext{
*Correspondence: jhardebeck@usgs.gov
}

U.S. Geological Survey, Menlo Park, CA, USA drop we would expect to see a coseismic stress change expressed as a stress rotation, while if the differential stress is substantially larger we would not expect any observable stress changes.

Rotations of the principal stress axes have been observed following recent great subduction zone earthquakes (e.g., Hasegawa et al. 2011, 2012; Hardebeck 2012; Chiba et al. 2012; Yang et al. 2013). These rotations usually take the form of a change in the plunge of the maximum compressive stress axis, $\sigma 1$, and can also involve a horizontal rotation of the trend of the sub-horizontal $\sigma 1$ axis. These stress rotations imply that the absolute stress level in subduction zones is low, on the order of earthquake stress drops of $\sim 10 \mathrm{MPa}$, and that stress drop in great earthquakes is nearly complete. Stress rotations would not be observed if the differential stress was on the order of $100 \mathrm{MPa}$, as predicted from laboratory observations of fault frictional strength assuming hydrostatic pore pressure. Low differential stress may be related to 
high pore fluid pressure or other mechanisms reducing the frictional strength of faults. Relating stress rotations to other properties of subduction zones may therefore lead to further understanding of the role of elevated fluid pressure and near-complete stress drop in subduction zone dynamics.

Lay et al. (2012) propose a depth-dependent model of the slip behavior of subduction megathrust faults. The topmost zone, called zone A, extends from the trench to $15 \mathrm{~km}$ depth and produces long-period tsunami earthquakes. Zone B, from 15 to $35 \mathrm{~km}$ depth, hosts large patches of large slip in great earthquakes, with little highfrequency radiated energy. Zone $C$, from 35 to $55 \mathrm{~km}$ depth, exhibits moderate coseismic slip and radiates more high-frequency energy from smaller slip patches. Zone D, which hosts tremor and slow slip events, exists in only some subduction zones and overlaps zone B and zone $C$ at $30-45 \mathrm{~km}$ depths. The boundary between zones $\mathrm{B}$ and $\mathrm{C}$ roughly corresponds to the Moho depth in the overriding plate. There is seismological evidence that high fluid pressure exists in the slab at and above the Moho depth of the overriding plate (e.g., Shelly et al. 2006; Audet et al. 2009). Hardebeck (2012) observed that $M \geq 8$ subduction zone earthquakes in zone B generally exhibit stress rotations, while those in zone $C$ generally did not, potentially linking stress rotations to both radiated energy and fluid pressure. However, that study was limited by assigning a single depth to each great earthquake, while in reality the rupture of a $M \geq 8$ subduction zone earthquake has a large down-dip width.

Stress rotations have been analyzed by some researchers (e.g., Hasegawa et al. 2011; Hardebeck 2012) using the theoretical framework of Hardebeck and Hauksson (2001). A simple analytic solution relates the average stress rotation over a given rupture area to the ratio between the earthquake stress drop and the differential stress. However, this may oversimplify the spatial patterns of the stress rotations. In particular, the coseismic stress changes are modeled as the tensor representation of the mainshock stress drop, implicitly assuming that the observed stress changes are mainly sampling the stress shadow (e.g., Harris and Simpson 1996) of relieved stress around the mainshock rupture surface. If much of the observed stress rotation occurs outside of the stress shadow, i.e., beyond the ends of the earthquake rupture, the Hardebeck and Hauksson (2001) analytical solution may not be a good approximation.

Therefore, better imaging of the spatial areas where stress changes occur following great megathrust earthquakes is needed. Constraints on the down-dip extent of the stress changes would relate near-complete stress drop to other observables, such as radiated energy (e.g., Lay et al. 2012) and seismological evidence for fluids (e.g.,
Audet et al. 2009), and inform physical models. Testing whether the stress rotations are contained within the rupture area or extend past the ends of the rupture would illuminate whether simple models relating stress rotations to differential stress are generally applicable.

Some observed coseismic stress rotations are followed by a back-rotation to the pre-mainshock stress orientation within the first few months to years following the mainshock (e.g., Hardebeck 2012). The back-rotation reflects stress reloading of the mainshock rupture area, and therefore may provide insight into postseismic processes. The observed reloading is too rapid to be due to tectonic loading alone and must therefore be due to transient processes such as afterslip and viscoelastic relaxation. Additionally, afterslip in the mainshock rupture zone may continue unloading the fault and may cause a postseismic rotation in the same direction as the coseismic rotation. Comparing the spatial distribution of the postseismic stress rotation to the locations of observed afterslip may shed light on the relative importance of afterslip in the reloading and/or continued unloading of the stress on the mainshock rupture zone. Additionally, the coseismic rotations may be partially obscured by the postseismic rotations, if the postmainshock time period contains a rapid rotation. Understanding the mechanism for the postseismic rotation may help correct for this problem and better capture the coseismic rotation.

In this study, I explore the spatial distribution of coseismic and postseismic stress rotations as a function of depth and along-strike distance for three recent $M \geq 8.8$ subduction zone earthquakes.

\section{Methods}

I consider three megathrust earthquakes: the 2011 M9.0 Tohoku-Oki earthquake (e.g., Hirose et al. 2011), the 2010 M8.8 Maule earthquake (e.g., Madariaga et al. 2010), and the 2004 M9.3 Sumatra-Andaman earthquake (e.g., Lay et al. 2005). Each of these earthquakes has been shown to have significantly altered the stress field (e.g., Hasegawa et al. 2011, 2012; Hardebeck 2012). In this study, I determine the spatial distribution of the coseismic and postseismic stress rotations from inversion of earthquake moment tensors. I compare the spatial extent of the coseismic rotation to published finite rupture models of the mainshock, both along-strike and downdip, and with the depth-dependent megathrust zones defined by Lay et al. (2012). I also compare the postseismic rotations to published models of the spatial distribution of afterslip.

I use moment tensors from the NIED catalog (Kubo et al. 2002) for the Tohoku-Oki earthquake sequence, the Global CMT (GCMT) catalog (Ekström et al. 2012) for the Sumatra-Andaman earthquake sequence, and 
a combined catalog of GCMT solutions and regional moment tensors from Hayes et al. (2013) for the Maule earthquake sequence. The Tohoku-Oki earthquake has the densest data coverage, while the Sumatra-Andaman earthquake has the sparsest coverage. A spatial area around each mainshock rupture is selected, and all earthquakes within that region and within $20 \mathrm{~km}$ above or below the SLAB1.0 plate interface model (Hayes et al. 2012) are used. This is intended to capture the stress field in which the rupture surface is embedded, and may include events from the upper and lower plates, as well as the plate interface. Inverting these events together assumes that the plate interface is not a stress boundary. If there is a substantial stress orientation change across the plate interface, it will appear in the inversion results as stress heterogeneity.

To determine the pre-mainshock stress, all events from the beginning of the catalog (January 1997 for NIED, January 1977 for GCMT) until the time of the mainshock are used. The postmainshock time extends through September 2016 for the Tohoku-Oki earthquake, July 2016 for the Sumatra-Andaman earthquake, and for the Maule earthquake, until the time of the nearby 2015 M8.3 Ilapel earthquake. The postmainshock periods for the TohokuOki and Maule sequences are divided into three time periods with roughly the same number of aftershocks (the Tohoku-Oki aftershocks are divided into the first 3 months, the next 1 year, and the next $\sim 4$ years. The Maule aftershocks are divided into the first 2 months, the next 4 months, and the next $\sim 5$ years). For the Sumatra-Andaman earthquake, the postmainshock period is divided into four time periods separated by the nearby 2005 M8.6 Nias-Simeulue earthquake ( 3 months later), 2007 M8.4 Mentawi earthquake (another 2.5 years later), and 2012 M8.6 Indian Ocean earthquake (another $\sim 4.5$ years later), to isolate any possible stress changes due to these events.

The moment tensors are inverted for stress orientation using the Spatial and Temporal Stress Inversion (SATSI) method of Hardebeck and Michael (2006). The earthquakes are binned with $0.5^{\circ}$ spacing in latitude and longitude, and into the pre-mainshock and postmainshock time periods described above. Each spatial-temporal bin is inverted for stress orientation, with a flattening constraint to minimize the difference in stress orientation between adjacent spatial bins and between consecutive time periods. The spatial and temporal damping parameters are found from trade-off curves between the data misfit and model length. All spatial-temporal bins are included in the inversion, and results are reported for those with at least 6 earthquakes. The uncertainty in the stress tensor is found by inverting 3000 bootstrap resamplings of the data. One of the two nodal planes of each moment tensor is selected randomly for each bootstrap resampling to account for the nodal plane ambiguity.

The mean misfit of the moment tensors to the best fitting stress orientation is $10^{\circ}-15^{\circ}$ for the Maule and Sumatra-Andaman catalogs, and $35^{\circ}$ for the TohokuOki catalog. This suggests some unmodeled stress variations in Tohoku, although the misfit for all three catalogs is low enough to indicate that the inversion successfully retrieved the homogeneous part of the stress field. Michael (1991) used synthetic tests to show that the homogeneous part of the stress tensor can be retrieved if it has larger amplitude than the heterogeneous part. For moment tensors with errors of $\sim 15^{\circ}$, like the NIED and GCMT catalogs (Kubo et al. 2002; Frohlich and Davis 1999), Michael (1991) found that the homogeneous part of the stress tensor is larger than the heterogeneous part and can be retrieved if the mean misfit is $<45^{\circ}$.

I define the coseismic rotation as the difference between the pre-mainshock and the first postmainshock time periods. I use the rotation between each pair of consecutive postmainshock time periods to characterize the postseismic rotation. I determine both the vertical rotation, i.e., the change in plunge of the maximum compressive stress axis, $\sigma 1$, and the horizontal rotation, i.e., the change in the trend of the maximum horizontal stress direction, SHmax. Uncertainty in the vertical and horizontal rotations is found from the 3000 realizations of the stress inversion with bootstrap resampling.

\section{Results}

For all three mainshocks, the coseismic and postseismic stress rotations occur in generally the same area as the largest mainshock slip (Figs. 1, 2, 3). For the Tohoku earthquake (Fig. 1), coseismic stress rotations are observed offshore in an area extending from $35^{\circ} \mathrm{N}$ to $39.5^{\circ} \mathrm{N}$ latitude, with the largest rotations corresponding to and south of the region where the largest coseismic slip was observed. This is similar to results of Hasegawa et al. (2012) which show significant stress rotations in the hanging wall between about $36.5^{\circ} \mathrm{N}$ and $39^{\circ} \mathrm{N}$ latitude. The largest vertical rotations occur within and down-dip of the largest mainshock rupture area, while the largest horizontal rotations occur at a range of depths. The largest postseismic rotations cover a similar spatial area, with both the vertical and horizontal rotations generally updip of the area of largest afterslip.

For the Maule earthquake (Fig. 2), the coseismic stress rotations span $38^{\circ} \mathrm{S}-34^{\circ} \mathrm{S}$, the full length of the observed mainshock rupture, with the postseismic stress rotations spanning a similar region. The rotations occur within the depth range of the largest rupture area. For the Sumatra earthquake (Fig. 3), large coseismic rotations are observed between $4^{\circ} \mathrm{N}$ and $7^{\circ} \mathrm{N}$, where the largest 

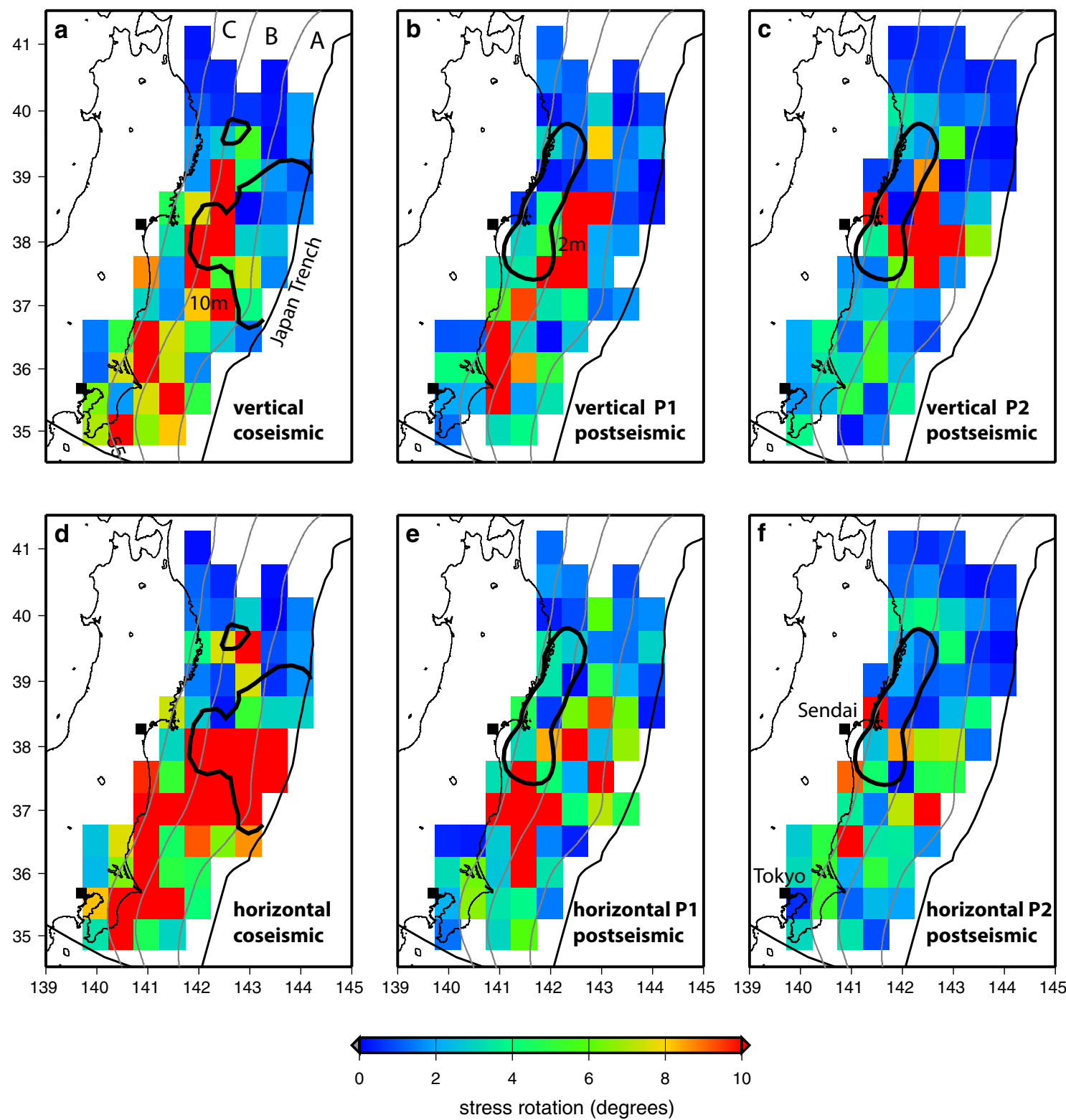

Fig. 1 Stress rotations following the 2011 M9.0 Tohoku-Oki earthquake. Shown are both the vertical rotation, i.e., the change in plunge of the $\sigma 1$ axis, and the horizontal rotation, i.e., the change in trend of the SHmax direction, for $0.5^{\circ} \times 0.5^{\circ}$ spatial bins. a Vertical coseismic rotation, the change between the pre-mainshock (1997-2-16-2011-3-11) and first postmainshock (2011-3-11-2011-6-11) time periods. Thick black lines indicate the 10-m contour of the mainshock slip model of Minson et al. (2014), b vertical postseismic rotation P1, between the first and second (2011-6-11-2012-6-11) postmainshock time periods. Thick black lines indicate the 2-m contour of the postseismic slip model of Ozawa et al. (2011), c vertical postseismic rotation P2, between the second and third (2012-6-11-2016-9-17) postmainshock time periods, $\mathbf{d}$ horizontal coseismic rotation, e horizontal postseismic rotation $\mathrm{P} 1, \mathbf{f}$ horizontal postseismic rotation $\mathrm{P} 2$

mainshock slip occurred, while some rotations extend to the northern end of the rupture at about $13^{\circ} \mathrm{N}$. Postseismic rotations occur over this zone as well as south to $0^{\circ} \mathrm{N}$, although the southernmost stress perturbations are likely associated with the 2005 M8.6 Nias-Simeulue earthquake.
In the down-dip direction, the largest coseismic stress rotations are generally found in zone B of Lay et al. (2012). For the Tohoku-Oki earthquake (Fig. 4a), the largest coseismic stress rotation is the lower part of zone $\mathrm{B}$ and the rotation extends into the upper part of zone C. The Moho depth of the overriding plate is $30-35 \mathrm{~km}$, 

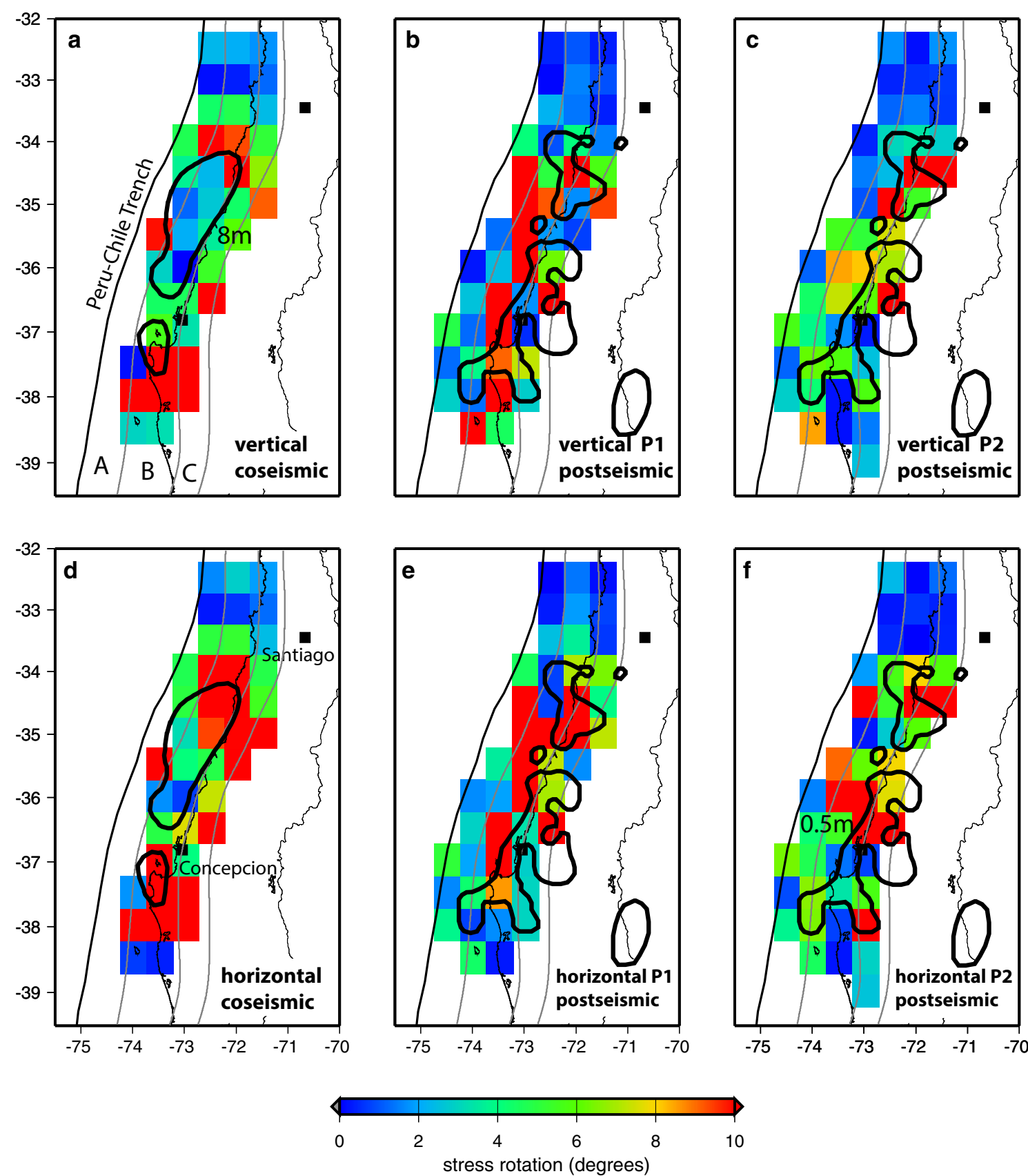

Fig. 2 Stress rotations following the 2010 M8.8 Maule earthquake. a Vertical coseismic rotation, the change between the pre-mainshock (1977-520-2010-2-27) and first postmainshock (2010-2-27-2010-4-30) time periods. Thick black lines indicate the 8-m contour of the mainshock slip model of Moreno et al. (2012), b vertical postseismic rotation P1, between the first and second (2010-4-30-2010-8-31) postmainshock time periods. Thick black lines indicate the 0.5 -m contour of the postseismic slip model of Lin et al. (2013), c vertical postseismic rotation P2, between the second and third (2010-8-31-2015-9-16) postmainshock time periods, $\mathbf{d}$ horizontal coseismic rotation, e horizontal postseismic rotation P1, f horizontal postseismic rotation P2

shallowing toward the trench (Zhao et al. 1994), meaning that much of the rotation is below the Moho depth. In contrast, the largest slip in most finite rupture models is in the upper part of zone B and in zone A (e.g., Shao et al. 2011; Yagi and Fukahata 2011; Yamazaki et al. 2011; Minson et al. 2014), while the model of Ide et al. (2011) places a second peak of slip at the base of zone C. For the Tohoku-Oki earthquake, the largest coseismic stress 

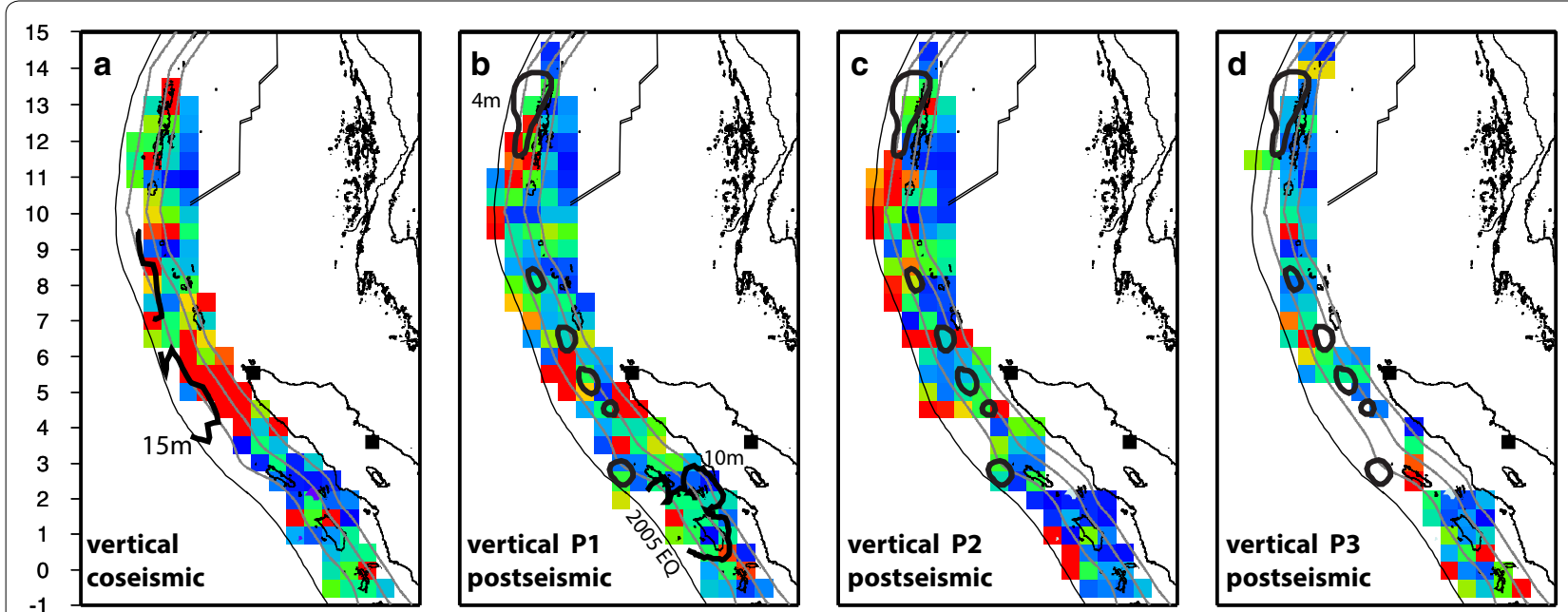

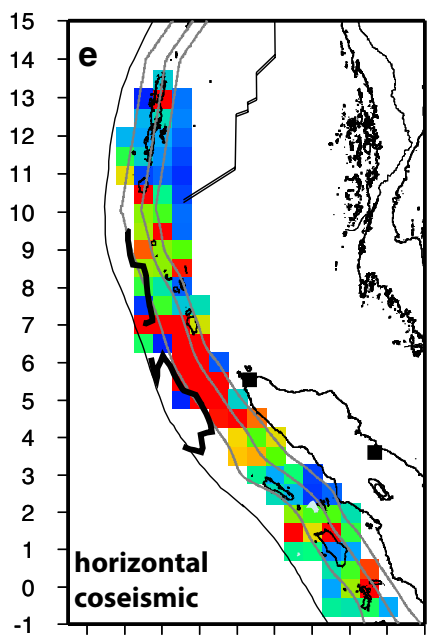

919293949596979899100

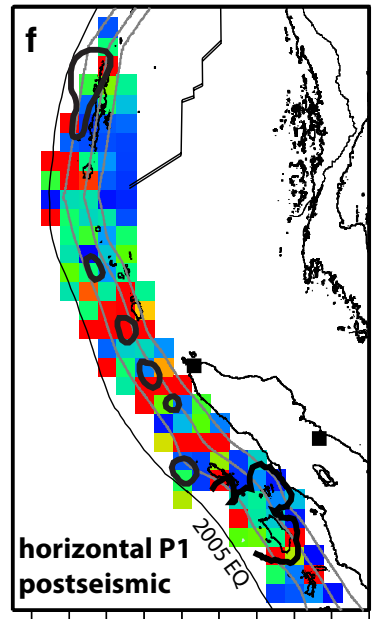

919293949596979899100

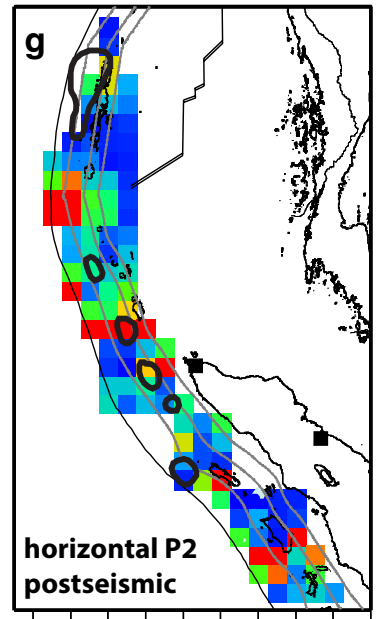

919293949596979899100

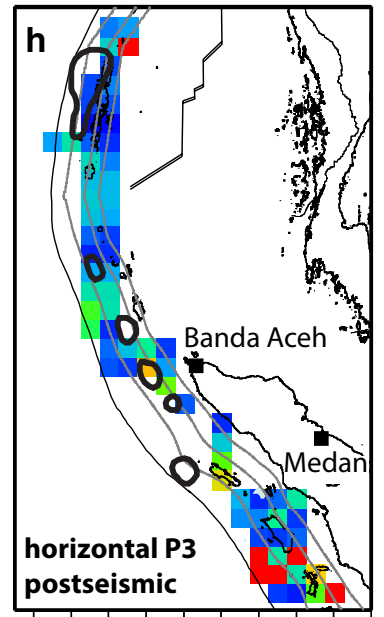

919293949596979899100

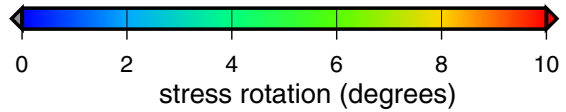

Fig. 3 Stress rotations following the 2004 M9.3 Sumatra-Andaman earthquake. a Vertical coseismic rotation, the change between the pre-mainshock (1977-5-20-2004-12-26) and first postmainshock (2004-12-26-2005-3-28) time periods. Thick black lines indicate the 15-m contour of the 2004 M9.3 mainshock slip model of Rhie et al. (2007), b vertical postseismic rotation P1, between the first and second (2005-3-28-2007-9-12) postmainshock time periods. Thick black lines indicate the 4-m contour of the postseismic slip model of Chlieh et al. (2007), and the southernmost contour is the 10-m contour of the 2005 M8.6 Nias-Simeulue earthquake slip model of Ji (2005), c vertical postseismic rotation P2, between the second and third (2007-9-12-2012-4-11) postmainshock time periods, d vertical postseismic rotation P3, between the third and fourth (2012-4-11-2016-9-17) postmainshock time periods, e horizontal coseismic rotation, $\mathbf{f}$ horizontal postseismic rotation P1, $\mathbf{g}$ horizontal postseismic rotation P2, $\mathbf{h}$ horizontal postseismic rotation $\mathrm{P} 3$

rotations therefore appear to occur at the down-dip edge of the shallow area of large slip. For the Sumatra earthquake (Fig. 4e), the largest coseismic rotation is also observed at the base of zone $\mathrm{B}$, with rotation extending into the upper part of zone $C$. There is no good agreement on the depth of earthquake rupture between different models, with the depth range of the largest slip ranging from zone A to the top of zone C (e.g., Ammon et al. 2005; Rhie et al. 2007; Chlieh et al. 2007). The Maule earthquake (Fig. 4c) exhibits a more shallow stress rotation than the other two events, with the largest coseismic stress rotation in the middle of zone B. The largest slip of the Maule rupture models is generally in the middle to lower part of zone B (e.g., Delouis 

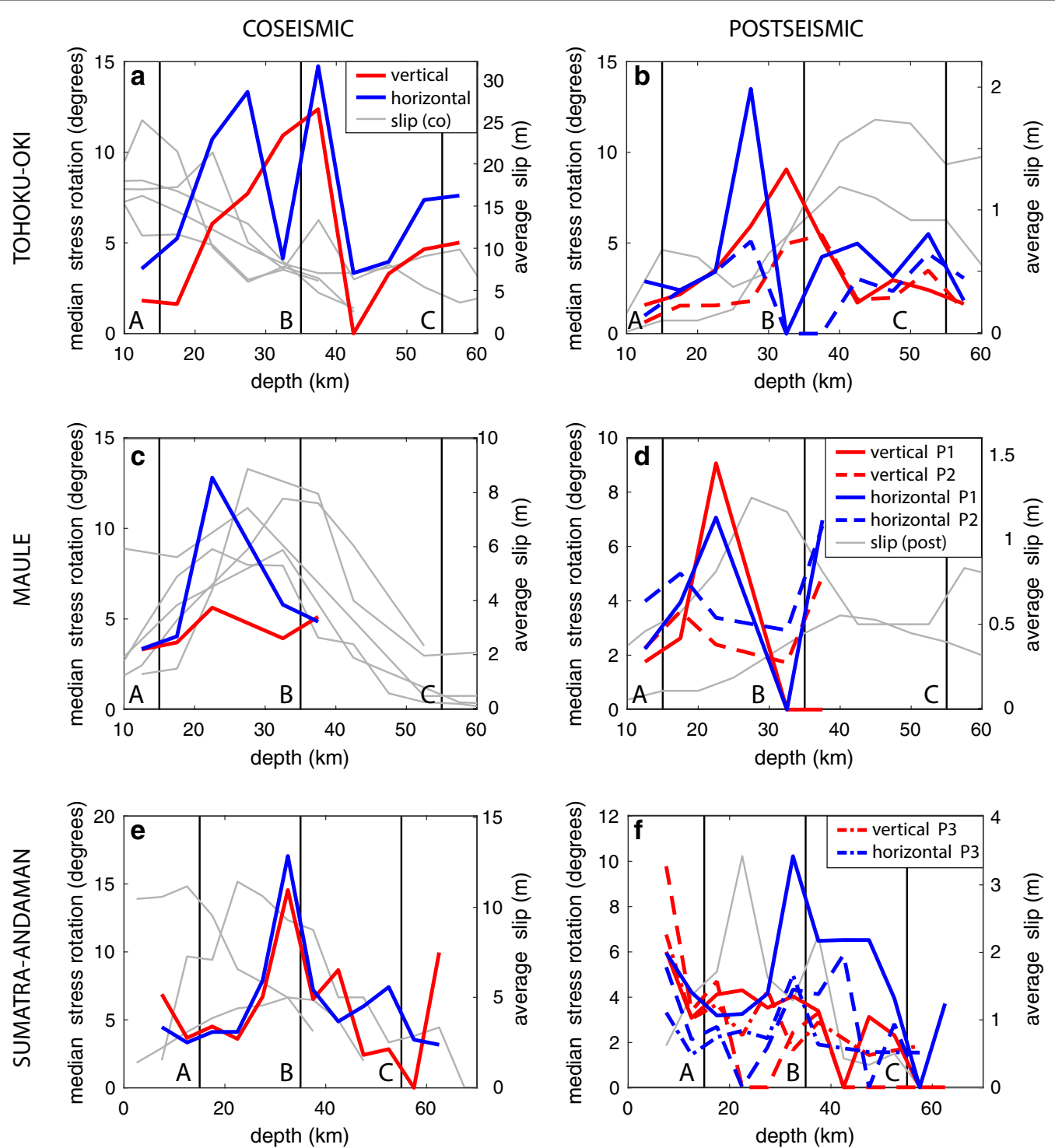

Fig. 4 Stress rotation as a function of subduction interface depth. The median vertical (red) and horizontal (blue) stress rotations are found for all inversion bins in 5-km depth intervals. Multiple realizations are performed by sampling a rotation for each bin from its bootstrap uncertainty, and the median is set to zero if it is not significantly different from zero at 1-sigma uncertainty. Vertical black lines and letters separate zones $A, B$, and C, as defined by Lay et al. (2012). a Tohoku-Oki earthquake coseismic stress rotation. Gray curves indicate average mainshock slip as a function of depth from slip models of Shao et al. (2011), Ide et al. (2011), Yagi and Fukahata (2011), Yamazaki et al. (2011) and Minson et al. (2014). b Tohoku-Oki earthquake postseismic stress rotation, P1 shown as solid lines and P2 as dashed lines. Gray curves indicate average afterslip as a function of depth from models of Ozawa et al. (2011) and Yamagiwa et al. (2015). c Maule earthquake coseismic stress rotation. Gray curves indicate mainshock slip models of Delouis et al. (2010), Lorito et al. (2011), Moreno et al. (2012), Pollitz et al. (2011) and Yue et al. (2014). d Maule earthquake postseismic stress rotation, P1 shown as solid lines and P2 as dashed lines. Gray curves indicate afterslip models of Bedford et al. (2013) and Lin et al. (2013). e Sumatra-Andaman earthquake coseismic stress rotation. Gray curves indicate mainshock slip models of Ammon et al. (2005), Rhie et al. (2007) and Chlieh et al. (2007), f Sumatra-Andaman earthquake postseismic stress rotation, P1 shown as solid lines, P2 as dashed lines, and P3 as dash-dot lines. Gray curve indicates afterslip model of Chlieh et al. (2007), black curve the 2005 M8.6 Nias-Simeulue earthquake slip model of Ji (2005)

et al. 2010; Lorito et al. 2011; Pollitz et al. 2011; Moreno et al. 2012; Yue et al. 2014). For the Maule earthquake, the largest coseismic stress rotations therefore appear to occur in the middle or near the up-dip edge of the largest rupture area.
The coseismic stress rotations tend to have similar along-strike extent as the mainshock rupture. For the Tohoku earthquake (Fig. 5a), the largest slip is concentrated between $36.4^{\circ} \mathrm{N}$ and $38.5^{\circ} \mathrm{N}$. For the Maule earthquake (Fig. 5c), the slip models generally exhibit 

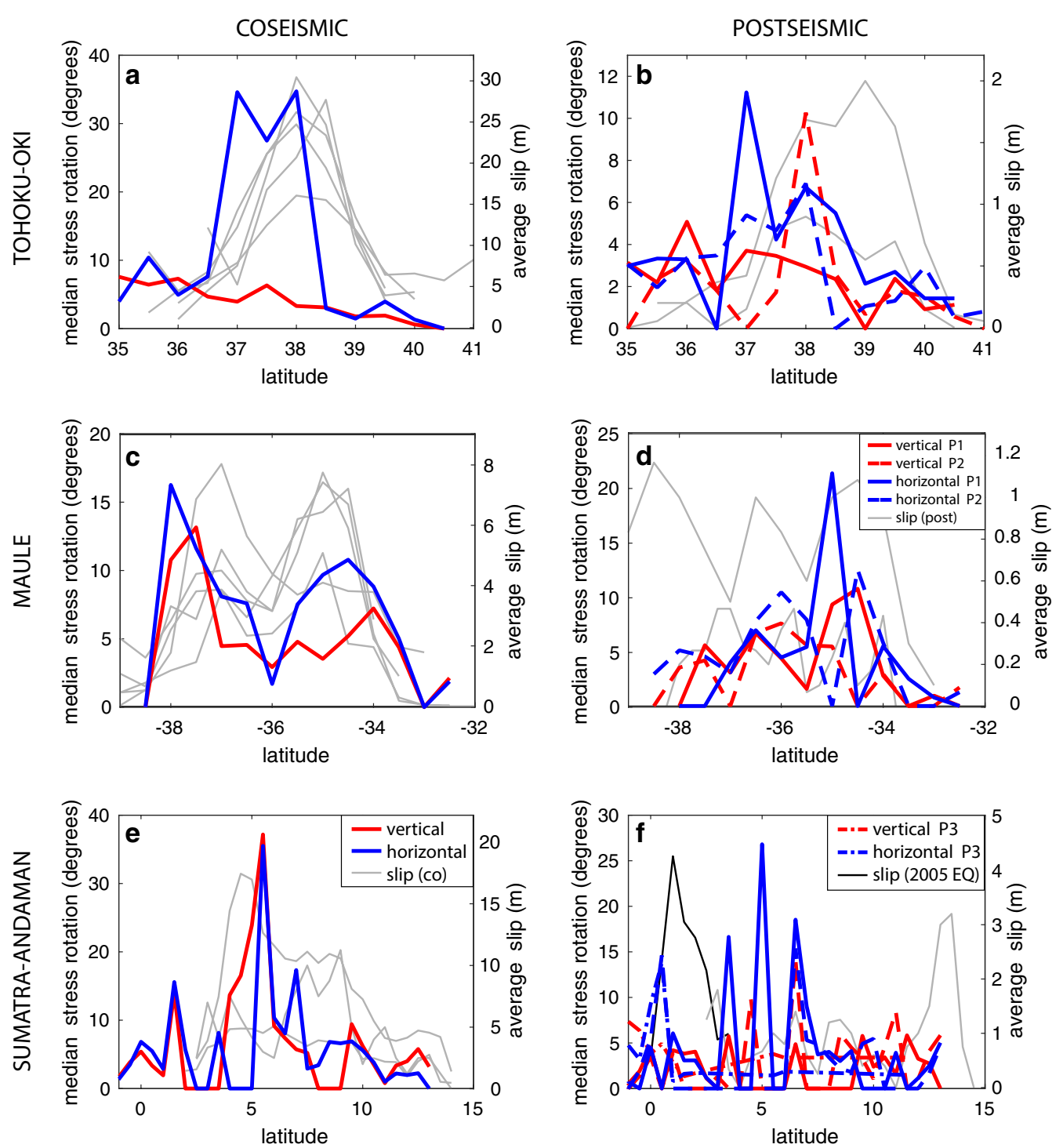

Fig. 5 Stress rotation as a function of latitude, a proxy for along-strike distance. The median vertical (red) and horizontal (blue) stress rotation is found for all inversion bins in $0.5^{\circ}$ latitude intervals. Multiple realizations are performed by sampling a rotation for each bin from its bootstrap uncertainty, and the median is set to zero if it is not significantly different from zero at 1-sigma uncertainty. Gray curves indicate average mainshock slip or average afterslip as a function of latitude, from the same models as in Fig. 4. a Tohoku-Oki earthquake coseismic stress rotation, $\mathbf{b}$ TohokuOki earthquake postseismic stress rotation, P1 shown as solid lines and P2 as dashed lines, c Maule earthquake coseismic stress rotation, $\mathbf{d}$ Maule earthquake postseismic stress rotation, P1 shown as solid lines and P2 as dashed lines, e Sumatra-Andaman earthquake coseismic stress rotation. $\mathbf{f}$ Sumatra-Andaman earthquake postseismic stress rotation, P1 shown as solid lines, P2 as dashed lines, and P3 as dash-dot lines

a bimodal slip distribution with a low at about $36^{\circ} \mathrm{S}$. The stress rotations exhibit a similar bimodal distribution with a low at $36^{\circ} \mathrm{S}$, with peaks at $34^{\circ} \mathrm{S}-34.5^{\circ} \mathrm{S}$ and $37.5^{\circ} \mathrm{S}-38^{\circ} \mathrm{S}$ similar to the peaks in the rupture. For the Sumatra earthquake (Fig. 5e), the stress rotations and two of the three slip distributions (Ammon et al. 2005; Rhie et al. 2007) peak at around $5^{\circ} \mathrm{N}$ and drop off rapidly to the south while tapering off more slowly to the north. An additional area of stress rotation is observed just south of the rupture zone at $1.5^{\circ} \mathrm{N}$.
Postseismic stress rotations tend to occur in the same along-strike and down-dip locations as the coseismic stress rotations, rather than being clearly related to the spatial extent of observed afterslip. For the Tohoku earthquake, the postseismic stress rotations are largest at the base of zone B and the top of zone C (Fig. 4b), while the largest afterslip occurs in the middle of zone $\mathrm{C}$ (Ozawa et al. 2011; Yamagiwa et al. 2015). The postseismic stress rotation extends south of the coseismic rotation, while the afterslip is centered somewhat north of the mainshock 
slip (Fig. 5b). For the Maule earthquake, the postseismic rotations mainly occur in the middle of zone B (Fig. 4d), while the afterslip models range from the lower part of zone B to zone C (Bedford et al. 2013; Lin et al. 2013). Along-strike, the postseismic rotations are largest in the north of the two mainshock slip patches, while the afterslip is distributed more evenly across the along-strike extent of the mainshock (Fig. 5d). For the Sumatra earthquake, the largest postseismic rotations are in the lower part of zone $\mathrm{B}$ and the upper part of zone $\mathrm{C}$, with another area of rotation in zone A (Fig. 4f), while the largest afterslip occurred in the middle of zone B (Chlieh et al. 2007). Along-strike, the largest postseismic rotations occur in the same locations as the coseismic rotation (Fig. 5f), with an additional rotation at $0^{\circ} \mathrm{N}$ that is probably related to the occurrence of the 2005 M8.6 Nias-Simeulue earthquake in that area. The largest afterslip, on the other hand, is near the northern end of the rupture zone.

For the Tohoku-Oki earthquake, $\sim 2 / 3$ of bins with a significant coseismic rotation $\geq 3^{\circ}$ experience a postseismic rotation of the opposite direction as the coseismic rotation, indicating reloading of the mainshock rupture area. For the Maule and Sumatra-Andaman earthquakes, only $\sim 1 / 3$ of such bins experience a postseismic rotation indicative of reloading. This implies that while reloading of the mainshock rupture occurs in some places, in many other places the stress on the rupture zone continues to be unloaded during the postseismic period.

\section{Discussion}

For all three $M \geq 8.8$ earthquakes, the largest coseismic stress rotations are found in the center to the lower end of zone B (15-35 km depth) of Lay et al. (2012), with rotation often extending into the upper part of zone $\mathrm{C}$ (35-55 km depth). The coseismic stress rotation is clearly deeper than the area of largest rupture for the TohokuOki earthquake and may be shallower for the Maule earthquake. This suggests that the mechanisms causing the stress rotation are closely connected with the properties of the lower end of zone B.

There are at least two possible physical mechanisms that could explain the stress rotations within the lower end of zone B. The first mechanism is that the differential stress level may be substantially lower there because of high fluid pressure. Audet et al. (2009) interpret receiver function images in Cascadia showing that the plate interface is a low-permeability barrier in the lower part of zone $\mathrm{B}$, confining fluids in the slab at high pressure, while this barrier is not present in zone C. Seismic tomography has also imaged high fluid pressures near the $\mathrm{B}-\mathrm{C}$ boundary (e.g., Shelly et al. 2006). Furthermore, seismic tomography in South America (Husen and Kissling 2001) shows what appear to be fluids rising from the slab into the crust of the overriding plate after a large earthquake fractures the low-permeability seal at the plate interface. The buildup and release of high-pressure fluids would repeat each seismic cycle (Sibson 2013). The periodic high fluid pressures would reduce fault strength in the slab and overriding plate, keeping the differential stress low. Stress rotations roughly scale with the ratio of the stress change to the differential stress, so a reduction in the differential stress would facilitate stress rotations.

The second mechanism is that near-complete stress drop may be easier to achieve in zone $B$ because of the large coherent slip patches that Lay et al. (2012) propose as the explanation for the lack of high-frequency radiation. The large patches of slip may represent areas of smooth fault surface, which may allow greater dynamic weakening during a large earthquake (e.g., Fang and Dunham 2013). Flat, smooth fault regions also appear to produce the largest earthquakes (Bletery et al. 2016). Near-complete stress drop would increase the ratio of the stress change to the differential stress, also facilitating stress rotation. While the stress drop may be near-complete in smooth fault regions, they are not necessarily the locations of the largest stress drop. If the background differential stress is relatively low, perhaps kept low by the greater dynamic weakening, the stress drop need not be unusually high to be near-complete. The stress drop cannot be fully complete, however, as the stress axes of the postmainshock stress field are resolvable and aftershocks occur. It is unclear why the large stress rotations would tend to occur near the base of zone B in this model, instead of throughout zone B.

The depth range of the stress rotations, from the lower part of zone $B$ to the top of zone $C$, is similar to the depth distribution of tremor and slow slip (e.g., Obara 2002; Rogers and Dragert 2003). These phenomena have not been observed in the same fault sections as the $M \geq 8.8$ earthquakes that are considered in this study, despite dense enough instrumentation to have detected tremor and slow slip elsewhere in Japan (Obara 2002) and Chile (Gallego et al. 2013). This suggests a shared physical mechanism that promotes tremor and slow slip in some cases and earthquakes with near-complete stress drop in others. High fluid pressure is a candidate mechanism, although this leaves unanswered the question of why some subduction zones produce tremor and slow slip while some do not.

For all three mainshocks, the coseismic stress rotations generally cover a spatial area similar to the area of largest mainshock slip. However, for the Tohoku-Oki earthquake, the depth distribution of the stress rotation clearly differs from the depth distribution of the earthquake rupture. This suggests that the Hardebeck and Hauksson (2001) analytical solution, which assumes that the stress rotation occurs 
in the mainshock stress shadow, may not be a good approximation. Additionally, the observed horizontal rotations and the spatial complexity of the vertical rotations are not consistent with the simple Hardebeck and Hauksson (2001) model, and suggest that heterogeneous earthquake slip contributes substantially to the observed stress rotations.

An alternative approach is to model the full spatial distribution of static stress changes due to the mainshock, and to map the observed stress changes with adequate resolution to compare to the modeled stress patterns of the direction and amplitude of the rotation (e.g., Yoshida et al. 2012; Hasegawa et al. 2012). Numerical inversion (Wesson and Boyd 2007; Yoshida et al. 2012; Yang et al. 2013) or forward modeling (e.g., Yoshida et al. 2014, 2015) can then be used to determine the background differential stress. This approach requires spatially mapping the stress rotation with a resolution that may not be possible for smaller or more poorly recorded events. Modeling difficulties may also be encountered close to the rupture where model discretization impacts the computed stress changes.

Postseismic stress rotations tend to occur in the same along-strike and down-dip locations as the coseismic stress rotations, rather than being clearly related to the spatial extent of observed afterslip. This may be explained by the near-complete coseismic stress drop, which leaves a region of very low differential stress just after the earthquake. Stress rotations scale with the ratio between the stress change and the differential stress. Therefore, the very low differential stress can facilitate large stress rotation in these areas, even if they are not the locations of greatest postseismic loading or unloading.

\section{Conclusions}

I explore the distribution of coseismic and postseismic stress rotations as a function of depth and along-strike distance for the 2011 M9.0 Tohoku-Oki, 2010 M8.8 Maule, and 2004 M9.3 Sumatra-Andaman earthquakes. The largest coseismic stress rotations are found in the mid- to lower part of zone $\mathrm{B}$, and rotations extend into the upper part of zone C, as defined by Lay et al. (2012). Lay et al. (2012) found decreased high-frequency radiated energy in zone B, suggesting large patches of continuous slip. These large slip patches may facilitate the near-complete stress drop implied by the coseismic stress rotations. Seismological studies (e.g., Shelly et al. 2006; Audet et al. 2009) imply that high-pressure fluids are present at the base of zone $\mathrm{B}$. High fluid pressure reduces the differential stress, facilitating coseismic stress rotations. The coseismic stress rotations are therefore potentially related to multiple physical properties of the subduction interface. The postseismic stress rotations tend to occur in the same locations as the coseismic rotations, which may be the result of the very low differential stress following the coseismic rotation.
The stress rotations are generally contained within the mainshock rupture area in the along-strike direction, although they can differ in their depth distribution. This suggests that the Hardebeck and Hauksson (2001) assumption that the stress rotation occurs in the mainshock stress shadow may not be generally applicable. Additionally, the observed horizontal rotations, as well as the spatial irregularity of the vertical rotations, suggest that heterogeneous earthquake slip contributes substantially to the observed stress rotations. This implies that the Hardebeck and Hauksson (2001) method for finding the differential stress from the coseismic stress rotation may be overly simplistic. More accurate results may be obtained by modeling the full spatial distribution of the mainshock static stress changes and finding the differential stress through inversion or forward modeling.

\section{Acknowledgements}

I am grateful to two anonymous reviewers, and David Shelly and Patricia McCrory for constructive reviews of an earlier version of this manuscript.

\section{Competing interests}

The authors declare that they have no competing interests.

\section{Availability of data and materials}

The National Research Institute for Earth Science and Disaster Prevention (NIED) moment tensor catalog is available online from the NIED at www.fnet. bosai.go.jp/fnet/event/search.php. The Global CMT (GCMT) moment tensor catalog is available online from the GCMT project at www.globalcmt.org/ CMTsearch.html. The regional moment tensors for Chile are available online from the US Geological Survey at: earthquake.usgs.gov/earthquakes/search. The SLAB 1.0 subduction zone interface model is available online from the US Geological Survey at: earthquake.usgs.gov/data/slab. The SATSI code used for stress inversion is available online from the US Geological Survey at: earthquake.usgs.gov/research/software/\#SATSI. The earthquake rupture models and afterslip models are taken from the cited publications or downloaded from the Finite-Source Rupture Model Database at equake-rc.info/SRCMOD/.

\section{Publisher's Note}

Springer Nature remains neutral with regard to jurisdictional claims in published maps and institutional affiliations.

Received: 27 January 2017 Accepted: 12 May 2017

Published online: 18 May 2017

\footnotetext{
References

Ammon CJ, Ji C, Thio HK, Robinson D, Ni S, Hjorleifsdottir V, Kanamori H, Lay T, Das S, Helmberger D, Ichinose G (2005) Rupture process of the 2004 Sumatra-Andaman earthquake. Science 308(5725):1133-1139

Audet P, Bostock MG, Christensen NI, Peacock S (2009) Seismic evidence for overpressured subducted oceanic crust and megathrust fault sealing. Nature 457(7225):76-78

Bedford J, Moreno M, Baez JC, Lange D, Tilmann F, Rosenau M, Heidbach O, Oncken O, Bartsch M, Rietbrock A, Tassara A (2013) A high-resolution, time-variable afterslip model for the 2010 Maule Mw = 8.8, Chile megathrust earthquake. Earth Planet Sci Lett 383:26-36

Bletery Q, Thomas AM, Rempel AW, Karlstrom L, Sladen A, De Bar$\operatorname{ros} L$ (2016) Mega-earthquakes rupture flat megathrusts. Science 354(6315):1027-1031

Chiba K, lio Y, Fukahata Y (2012) Detailed stress fields in the focal region of the 2011 off the Pacific coast of Tohoku Earthquake-implication for the
} 
distribution of moment release. Earth Planets Space 64(12):1157-1165. doi:10.5047/eps.2012.07.008

Chlieh M, Avouac JP, Hjorleifsdottir V, Song TRA, Ji C, Sieh K, Sladen A, Hebert H, Prawirodirdjo L, Bock Y, Galetzka J (2007) Coseismic slip and afterslip of the great Mw 9.15 Sumatra-Andaman earthquake of 2004. Bull Seismol Soc Am 97(1A):S152-S173

Delouis B, Nocquet JM, Vallée M (2010) Slip distribution of the February 27, $2010 \mathrm{Mw}=8.8$ Maule earthquake, central Chile, from static and high-rate GPS, InSAR, and broadband teleseismic data. Geophys Res Lett. doi:10.10 29/2010GL043899

Ekström G, Nettles M, Dziewonski AM (2012) The global CMT project 2004-2010: centroid-moment tensors for 13,017 earthquakes. Phys Earth Planet Inter 200-201:1-9

Fang Z, Dunham EM (2013) Additional shear resistance from fault roughness and stress levels on geometrically complex faults. J Geophys Res 118(7):3642-3654

Frohlich C, Davis SD (1999) How well constrained are well-constrained T, B, and P axes in moment tensor catalogs? J Geophys Res 104:4901-4910

Gallego A, Russo RM, Comte D, Mocanu V, Murdie RE, VanDecar JC (2013) Tidal modulation of continuous nonvolcanic seismic tremor in the Chile triple junction region. Geochem Geophys Geosyst 14(4):851-863

Hardebeck JL (2012) Coseismic and postseismic stress rotations due to great subduction zone earthquakes. Geophys Res Lett. doi:10.1029/201 2GL053438

Hardebeck JL, Hauksson E (2001) Crustal stress field in southern California and its implications for fault mechanics. J Geophys Res 106(B10):21859-21882

Hardebeck JL, Michael AJ (2006) Damped regional-scale stress inversions: methodology and examples for southern California and the Coalinga aftershock sequence. J Geophys Res. doi:10.1029/2005JB004144

Harris RA, Simpson RW (1996) In the shadow of 1857-the effect of the Great Ft. Tejon Earthquake on subsequent earthquakes in southern California. Geophys Res Lett 23(3):229-232

Hasegawa A, Yoshida K, Okada T (2011) Nearly complete stress drop in the 2011 Mw 9.0 off the Pacific coast of Tohoku Earthquake. Earth Planets Space 63(7):703-707. doi:10.5047/eps.2011.06.007

Hasegawa A, Yoshida K, Asano Y, Okada T, linuma T, Ito Y (2012) Change in stress field after the 2011 great Tohoku-Oki earthquake. Earth Planet Sci Lett 355-356:231-243. doi:10.1016/j.epsl.2012.08.042

Hayes GP, Wald DJ, Johnson RL (2012) Slab1.0: a three-dimensional model of global subduction zone geometries. J Geophys Res. doi:10.1029/201 1JB008524

Hayes GP, Bergman E, Johnson KL, Benz HM, Brown L, Meltzer AS (2013) Seismotectonic framework of the 2010 February 27 Mw 8.8 Maule, Chile earthquake sequence. Geophys J Int 195(2):1034-1051

Hirose F, Miyaoka K, Hayashimoto N, Yamazaki T, Nakamura M (2011) Outline of the 2011 off the Pacific coast of Tohoku Earthquake (Mw 9.0)—Seismicity: foreshocks, mainshock, aftershocks, and induced activity. Earth Planets Space 63(7):513-518. doi:10.5047/eps.2011.05.019

Husen S, Kissling E (2001) Postseismic fluid flow after the large subduction earthquake of Antofagasta, Chile. Geology 29(9):847-850

Ide S, Baltay A, Beroza GC (2011) Shallow dynamic overshoot and energetic deep rupture in the $2011 \mathrm{Mw} 9.0$ Tohoku-Oki earthquake. Science 332(6036):1426-1429

Ji C (2005) Preliminary Result 05/03/28 (Mw 8.7), Sumatra Earthquake. www. tectonics.caltech.edu/slip_history/2005_sumatra/sumatra.html. Accessed 1 July 2013

Kubo A, Fukuyama E, Kawai H, Nonomura K (2002) NIED seismic moment tensor catalogue for regional earthquakes around Japan: quality test and application. Tectonophysics 356:23-48

Lay T, Kanamori H, Ammon CJ, Nettles M, Ward SN, Aster RC, Beck SL, Bilek SL, Brudzinski MR, Butler R, DeShon HR, Ekström G, Satake K, Sipkin S (2005) The great Sumatra-Andaman earthquake of 26 December 2004. Science 308(5725):1127-1133

Lay T, Kanamori H, Ammon CJ, Koper KD, Hutko AR, Ye L, Yue H, Rushing TM (2012) Depth-varying rupture properties of subduction zone megathrust faults. J Geophys Res. doi:10.1029/2011JB009133

Lin YNN, Sladen A, Ortega-Culaciati F, Simons M, Avouac JP, Fielding EJ, Brooks BA, Bevis M, Genrich J, Rietbrock A, Vigny C (2013) Coseismic and postseismic slip associated with the 2010 Maule Earthquake, Chile: characterizing the Arauco Peninsula barrier effect. J Geophys Res 118(6):3142-3159
Lorito S, Romano F, Atzori S, Tong X, Avallone A, McCloskey J, Cocco M, Boschi E, Piatanesi A (2011) Limited overlap between the seismic gap and coseismic slip of the great 2010 Chile earthquake. Nat Geosci 4(3):173-177

Madariaga R, Métois M, Vigny C, Campos J (2010) Central Chile finally breaks. Science 328(5975):181-182

Michael AJ (1991) Spatial variations in stress within the 1987 Whittier Narrows, California, aftershock sequence: new techniques and results. J Geophys Res 96:6303-6320

Minson SE, Simons M, Beck JL, Ortega F, Jiang J, Owen SE, Moore AW, Inbal A, Sladen A (2014) Bayesian inversion for finite fault earthquake source models_II: the 2011 great Tohoku-Oki, Japan earthquake. Geophys J Int 198(2):922-940

Moreno M, Melnick D, Rosenau M, Baez J, Klotz J, Oncken O, Tassara A, Chen J, Bataille K, Bevis M, Socquet A (2012) Toward understanding tectonic control on the Mw 8.82010 Maule Chile earthquake. Earth Planet Sci Lett 321:152-165

Obara K (2002) Nonvolcanic deep tremor associated with subduction in southwest Japan. Science 296(5573):1679-1681

Ozawa S, Nishimura T, Suito H, Kobayashi T, Tobita M, Imakiire T (2011) Coseismic and postseismic slip of the 2011 magnitude-9 Tohoku-Oki earthquake. Nature 475(7356):373-376

Pollitz FF, Brooks B, Tong X, Bevis MG, Foster JH, Bürgmann R, Smalley R, Vigny C, Socquet A, Ruegg JC, Campos J (2011) Coseismic slip distribution of the February 27, 2010 Mw 8.8 Maule, Chile earthquake. Geophys Res Lett. doi:10.1029/2011GL047065

Rhie J, Dreger D, Bürgmann R, Romanowicz B (2007) Slip of the 2004 SumatraAndaman earthquake from joint inversion of long-period global seismic waveforms and GPS static offsets. Bull Seismol Soc Am 97(1A):S115-S127

Rogers G, Dragert H (2003) Episodic tremor and slip on the Cascadia subduction zone: the chatter of silent slip. Science 300(5627):1942-1943

Shao G, Li X, Ji C, Maeda T (2011) Focal mechanism and slip history of the 2011 Mw 9/1 off the Pacific coast of Tohoku Earthquake, constrained with teleseismic body and surface waves. Earth Planets Space 63(7):559-564

Shelly DR, Beroza GC, Ide S, Nakamura S (2006) Low-frequency earthquakes in Shikoku, Japan, and their relationship to episodic tremor and slip. Nature 442:188-191. doi:10.1038/nature04931

Sibson RH (2013) Stress switching in subduction forearcs: implications for overpressure containment and strength cycling on megathrusts. Tectonophysics 600:142-152

Wesson RL, Boyd OS (2007) Stress before and after the 2002 Denali fault earthquake. Geophys Res Lett. doi:10.1029/2007GL029189

Yagi Y, Fukahata Y (2011) Rupture process of the 2011 Tohoku-Oki earthquake and absolute elastic strain release. Geophys Res Lett. doi:10.1029/201 $1 \mathrm{GL} 048701$

Yamagiwa S, Miyazaki SI, Hirahara K, Fukahata Y (2015) Afterslip and viscoelastic relaxation following the 2011 Tohoku-Oki earthquake (Mw9. 0) inferred from inland GPS and seafloor GPS/Acoustic data. Geophys Res Lett 42(1):66-73

Yamazaki Y, Lay T, Cheung KF, Yue H, Kanamori H (2011) Modeling near-field tsunami observations to improve finite-fault slip models for the 11 March 2011 Tohoku earthquake. Geophys Res Lett. doi:10.1029/2011GL049130

Yang YR, Johnson KM, Chuang RY (2013) Inversion for absolute deviatoric crustal stress using focal mechanisms and coseismic stress changes: the 2011 M9 Tohoku-oki, Japan, earthquake. J Geophys Res 118(10):5516-5529

Yoshida K, Hasegawa A, Okada T, linuma T, Ito Y, Asano Y (2012) Stress before and after the 2011 great Tohoku-Oki earthquake and induced earthquakes in inland areas of eastern Japan. Geophys Res Lett. doi:10.1029/2011 GL049729

Yoshida K, Hasegawa A, Okada T, linuma T (2014) Changes in the stress field after the 2008 M7.2 Iwate-Miyagi Nairiku earthquake in northeastern Japan. J Geophys Res 119:9016-9030. doi:10.1002/2014JB011291

Yoshida K, Hasegawa A, Okada T (2015) Spatially heterogeneous stress field in the source area of the $2011 \mathrm{Mw} 6.6$ Fukushima-Hamadori earthquake, NE Japan, probably caused by static stress change. Geophys J Int 201(2):1062-1071

Yue H, Lay T, Rivera L, An C, Vigny C, Tong X, Báez Soto JC (2014) Localized fault slip to the trench in the 2010 Maule, Chile Mw $=8.8$ earthquake from joint inversion of high-rate GPS, teleseismic body waves, InSAR, campaign GPS, and tsunami observations. J Geophys Res 119(10):7786-7804

Zhao D, Hasegawa A, Kanamori H (1994) Deep structure of Japan subduction zone as derived from local, regional, and teleseismic events. J Geophys Res Solid Earth 99(B11):22313-22329 